\title{
Grain size analytical and geochemical data of sediments from Ishakare and Alatan streams in Akungba-Akoko, Southwestern Nigeria
}

\author{
Olumuyiwa A. Odundun
}

\author{
Department of Earth Sciences, Adekunle Ajasin University, Akungba-Akoko, Ondo State, Nigeria. \\ Email: olumuyiwa.odundun@aaua.edu.ng
}

Copyright (C 2021 Odundun. This article remains permanently open access under the terms of the Creative Commons Attribution License 4.0, which permits unrestricted use, distribution, and reproduction in any medium, provided the original work is properly cited.

Received 17th February, 2021; Accepted 9th March, 2021

\begin{abstract}
The identification of anomalous elemental concentrations and the prediction of their dispersal pattern play a key role in geochemical exploration. Stream sediments are important focus in this aspect. Nine (9) sediment samples collected from Ishakare and Alatan Streams in Akungba-Akoko were subjected to grain size and inorganic geochemical analyses in order to determine their grain sizes distribution, travel distances, elemental concentrations and origin. Results of grain size analysis show that streams sediments are mostly medium-grained, poorly-moderately sorted and ranged from fine to strongly coarse skewed suggesting that they have been transported relatively not too far away from their sources under high to low energy. $\mathrm{SiO}_{2}$ is a dominant major oxide with concentration values ranging between 64.81 and $71.59 \mathrm{wt} . \%$ with a mean value of $68.07 \mathrm{wt} . \%$. Abundance of $\mathrm{Al}_{2} \mathrm{O}_{3}$ indicates that samples are from Aluminum-rich source bed rock. The weights of $\mathrm{Fe}_{2} \mathrm{O}_{3}$ and $\mathrm{TiO}_{2}$ also point to gneissic rocks as a probable source. Generally, concentrations of trace elements were found to be low indicating that the contamination statue of the sediments ranges from unpolluted to moderately polluted.
\end{abstract}

Keywords: Depositional environment, geoaccumulation, geochemical, provenance.

\section{INTRODUCTION}

Stream sediment mineralogy has been a useful technique which is available to geologists in their search for elements. This process of geochemical prospecting, according to Hawkes (1976) has its trace and earliest application in North America. Till date, stream sediment surveys remain a low-cost reconnaissance tool which is available for exploration. Additionally, dispersion of elements and their concentrations help to check the level of pollution within the sediment. Hence, sediments from Ishakare and Alatan streams were studied for their elemental and mineralogical composition. Most stream sediments in southwestern Nigeria are derived from the surrounding Basement Complex. In other places, they could originate from near the surface of exposed rocks of sedimentary and volcanic origins. Some of these are easily eroded whereas, others especially the crystalline and metamorphic rocks are affected by stream only when altered in surface layers (Adepoju and Adekoya, 2014;
Akintola et al., 2013). Additional sources of streams sediments are soils which inherited their mineral content (with some alterations) from bedrock of which in the tropic may consist completely of newly formed minerals. The importance of the knowledge of sources of these sediments cannot be overemphasized. Grain size analysis is, therefore, useful in provenance.

Previous research works (Folk, 1951; Visher, 1969; Odundun and Ogundoro, 2019) emphasized on classification of siliciclastic rocks (e.g. sandstone, claystone and siltstone). Some of these research works already described how the distribution of grain sizes in a siliciclastic rock or unconsolidated sediment sample may be related to their transport process and environment of deposition. This work considers existing methodologies and other mathematical approach in studying the stream samples from selected locations at Akungba-Akoko township, Ondo State. 


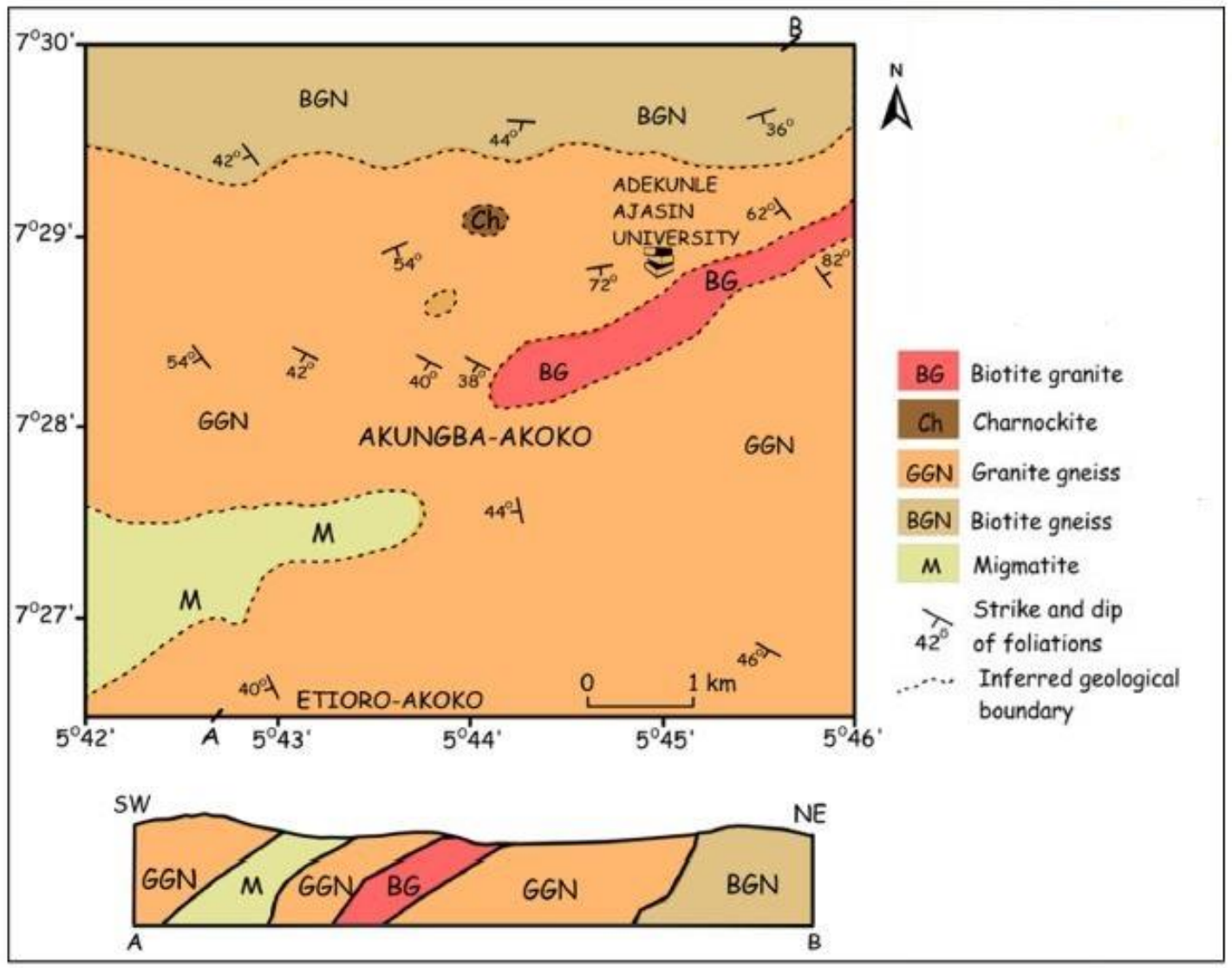

Figure 1. Geological map of the study area (Adapted from Ogunyele et al., 2019).

\section{Location of study area and geology}

The study area is in Akungba-Akoko, Akoko Southwest Local Government, Ondo State, Nigeria and lies within latitudes $N 7^{\circ} 25^{\prime}$ to $N 7^{\circ} 28^{\prime}$ and longitudes $E 5^{\circ} 40^{\prime}$ to $E 5^{\circ}$ $46^{\prime}$. Good road networks and footpath make the location easily assessable with elevation ranging from 301 to 386 $\mathrm{m}$ above sea level and a mean sea level of $352 \mathrm{~m}$. Landform features and relief of the area arise from geomorphological and geological processes that have shaped the area, which in turn control the composition of bedrocks and structures such as fractures and joints.

Geology of the area comprises rocks found within the southwest Nigeria Basement Complex (Rahaman, 1988). These include granite gneiss, biotite gneiss, pegmatites and charnockite. Granite gneiss is the most predominant rock type in the study area, as it covers $70 \%$ of the total area trending approximately Northeast to Southwest direction, mostly dipping in a southwest direction (Figure 1). The hills and inselbergs in the area are also composed of granite gneiss. Migmatites, also known as diaxite or mixed rocks, occur in the southwestern part of the study area. It is a frontier between igneous and metamorphic rocks. In the location, quartzitic and pegmatitic intrusions cut across this rock type in different directions.

\section{MATERIALS AND METHODS}

Nine (9) stream sediment samples were collected from three different locations of Akungba town. These locations are along the two seasonal streams as indicated in Figure 2 and labelled appropriately to avoid mix up. Materials used included a global positioning system (GPS) receiver, field and drainage maps, sample bags, paper tapes, field note book and stainless-steel scoop shovel. The scooped samples were thereafter taken to the laboratory for analysis.

\section{Grain size analysis}

Foremost, samples were dried after which they were placed on a large sheet of glazed paper and crushed with the fingers. The sediments were spread out and examined with a hand lens to make sure there were no aggregates present (Folk, 1980). The analysis was carried out using a sieve shaker at the departmental workshop of the Earth Sciences unit, Adekunle Ajasin University, AkungbaAkoko. The sieve sizes used for this operation are; $1.00 \mathrm{~m}$, $850 \mu \mathrm{m}, 600 \mu \mathrm{m}, 425 \mu \mathrm{m}, 300 \mu \mathrm{m}, 212 \mu \mathrm{m}, 180 \mu \mathrm{m}, 150$ $\mu \mathrm{m}$ and $90 \mu \mathrm{m}$. About $100 \mathrm{~g}$ of each of the nine samples 


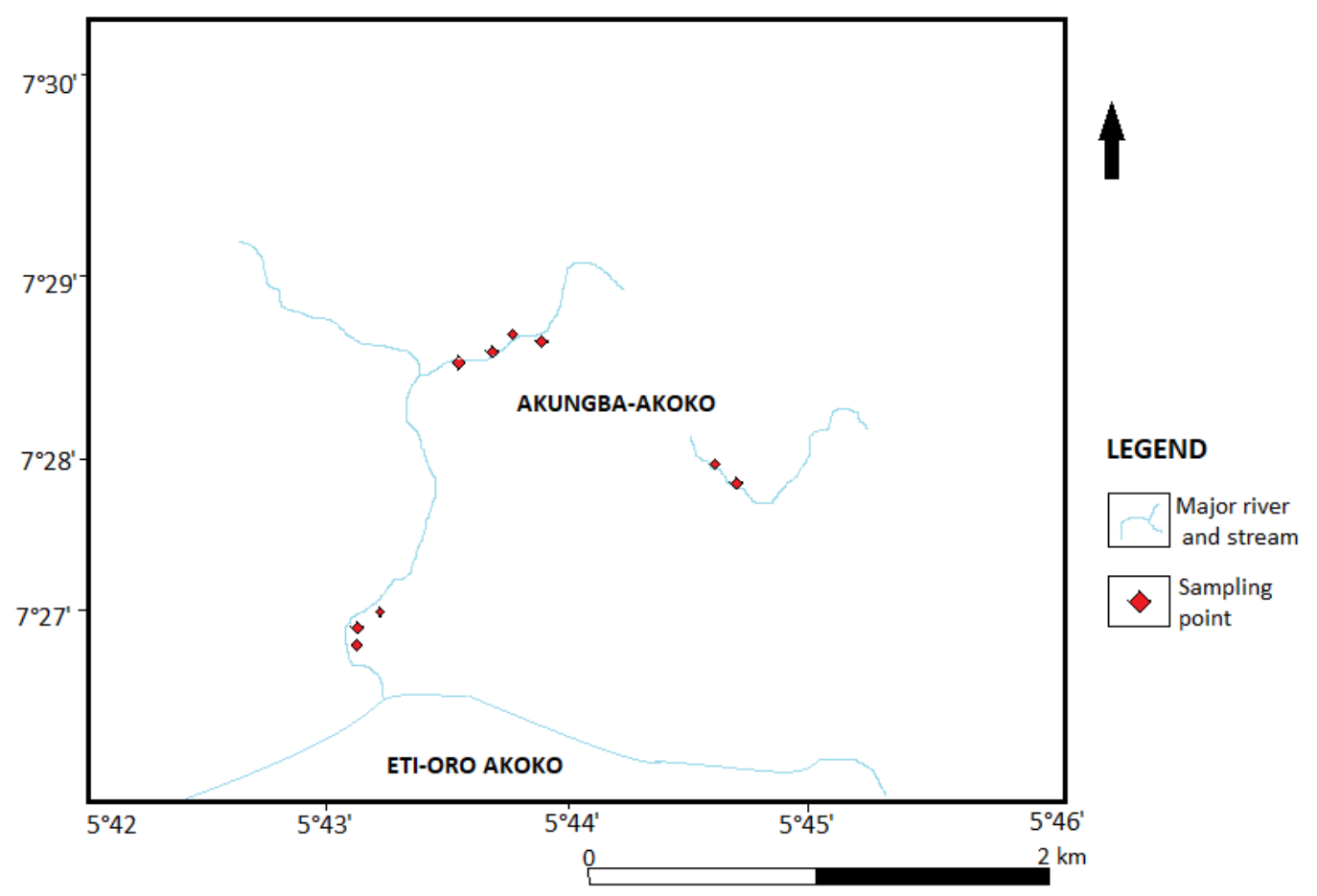

Figure 2. Map showing sample locations.

was weighed and poured into stacked sieve of the electric shaker and agitated for about 10 minutes. The fractions of samples left in the respective sieve was weighed and used for statistical calculations. Sizes of grains at different percentiles $\left(\varnothing_{5}, \varnothing_{16}, \varnothing_{25}, \varnothing_{50}, \varnothing_{75}, \varnothing_{84}\right.$ and $\left.\varnothing_{95}\right)$ were obtained from cumulative curve drawn and used in calculating parameters from the formula stated in equations (1) to (3) (Folk and Ward, 1957).

Graphic mean $(M)=\frac{\emptyset 16+\emptyset 50+\emptyset 84}{3}$

Standard deviation (sorting) $=\frac{\emptyset 84-\emptyset 16}{4}+\frac{\emptyset 95-\emptyset 5}{6.6}$

Graphic skewness $(\mathrm{SKI})=\varnothing_{95}-\varnothing_{5}$

\section{Geochemical analysis}

Energy dispersive X-ray fluorescence (EDXRF) spectrometer of model "Minipal 4" was used for this analysis which was carried out at the Quality Assurance Department of Dangote Cement Plant, Obajana, Kogi State. The samples were ground to fine powder using arget pulverizing machine (planetary micromill pulverisette 7). The process of pelletization came next by weighing $5 \mathrm{~g}$ of the pulverized sample into a beaker and mixed with $1 \mathrm{~g}$ of starch soluble. The mix was pressed under high pressure (6 tones) to produce pellets. The pellets were carefully placed in their respective measuring positions on a sample changer of the machine with the following conditions set (Dziunikowski, 1989) as the machine was switched on;

1. Elemental composition determination.

2. Nature of the samples to analyze as press powder (pellet).

3. The current used as $14 \mathrm{kv}$ for major oxides, $20 \mathrm{kv}$ for the trace elements/rare earth metals.

4. Selected filters were "kapton" for major oxides, Ag/Althin for the trace elements/rare earth metals.

The selection of filters was guided by a given periodic table used for elemental analysis. Time of measurement for each sample was 100 seconds and the medium used, throughout, was air. The machine was then calibrated by the machine's gain control, after which the respective samples were measured by clicking the respective positions of the sample changer. Loss on ignition (LOI) was determined gravimetrically by heating $1 \mathrm{~g}$ of the powdered sample in a cleaned weighed crucible at $1000^{\circ} \mathrm{C}$. After which the crucible and the content was weighed to get the difference in weight before and after heating (Dziunikowski, 1989).

\section{RESULTS AND DISCUSSION}

\section{Grain size analysis result}

Sieve analysis which was performed on the samples resulted in the following statistical parameters, the graphic 


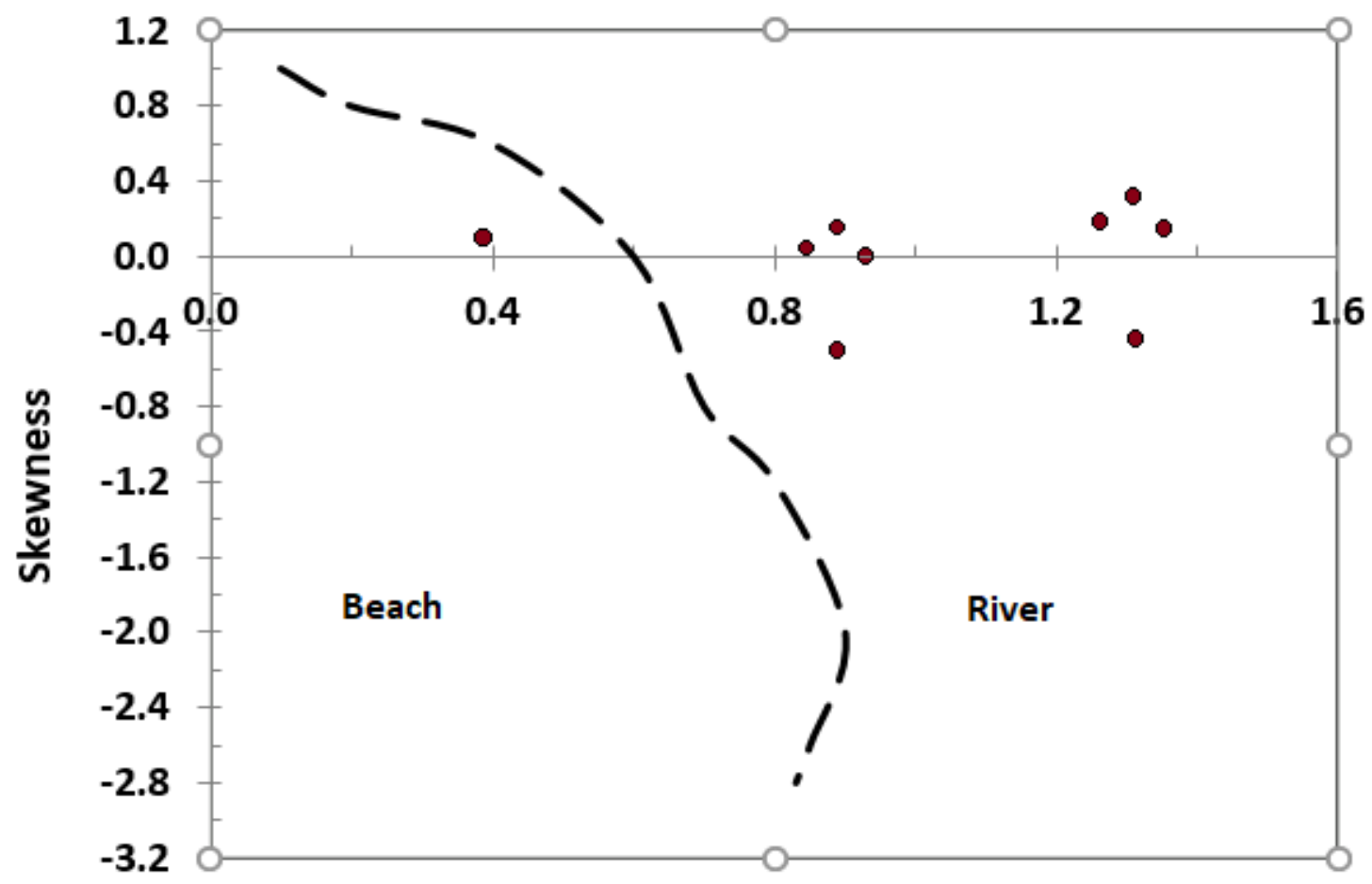

\section{Standard Deviation Values}

Figure 3. Bivariate plot of skewness against standard deviation.

mean, sorting (inclusive standard deviation) and inclusive graphic skewness.

Graphic mean aids in determining the overall size of the sediments, as it helps to decipher the nature of the source rock, mode and distance of transportation (Folk and Ward, 1957). The mean values of the samples range from 0.93 to $1.50 \varnothing$ which means that they are medium to coarsegrained (Folk, 1980) with more than $90 \%$ being medium grained.

Sorting is a measure of the standard deviation i.e., the spread of the grain size distribution. It is one of the most important parameters since it gives an indication of the effectiveness of the depositional medium in separating grains of different sizes. The values obtained for sorting ranged from 0.92 to $1.55 \varnothing$ with an average of $1.22 \varnothing$. This falls within the range of moderately sorted to poorly sorted. Such sediments according to Amaral and Pryor (1977) are deposited under variable current velocities and turbulence.

Skewness is a measure of the symmetry of the distribution of the sediments. It refers to the symmetry of the distribution and indicates whether the sediments have a tail of fine or coarse fraction. It is also a reflection of the depositional process. The values range between -0.04 and 0.48 . Such skewness is interpreted as near-symmetrical to strongly fine skewed. The average skewness value for the samples is 0.27 which falls in strongly fine skewed range. The skewness of the sediments is mainly positive (91.3\%) while $8.7 \%$ are negatively skewed. This is an indication that the sediments were deposited in a fluviatile depositional environment. According to Friedman (1979), river sands are generally positively skewed since most of the fines (i.e. clay and silts) have been removed by currents.

Bivariate plots which differentiate between river sands and beach sands (and based on skewness values against standard deviation) show that the results dominantly plot on river sands section indicating its dominance (Figure 3 ). The plots based on graphic mean value versus inclusive standard deviation suggests a dominant fluvial setting with some inland or surrounding wind-blown sand influence (Figure 4).

\section{Geochemical analysis result}

Result of the geochemical analysis for major oxides carried out is shown in Table 1. Results show that $\mathrm{SiO}_{2}$ is the dominant major element in oxides found within the stream sediments in the study area, with values ranging from 64.81 to $71.59 \mathrm{wt} \%$. $\mathrm{SiO}_{2}$ has the higher major elemental concentrations in the study area than the continental crust values of Gao et al. (1998) and Rudnick and $\mathrm{Gao}$ (2003). The highest value for $\mathrm{SiO}_{2}$ was in location $4 \mathrm{~A}$, with lowest value of $64.81 \mathrm{wt} . \%$ of $\mathrm{SiO}_{2}$ in location $1 \mathrm{~B}$. 


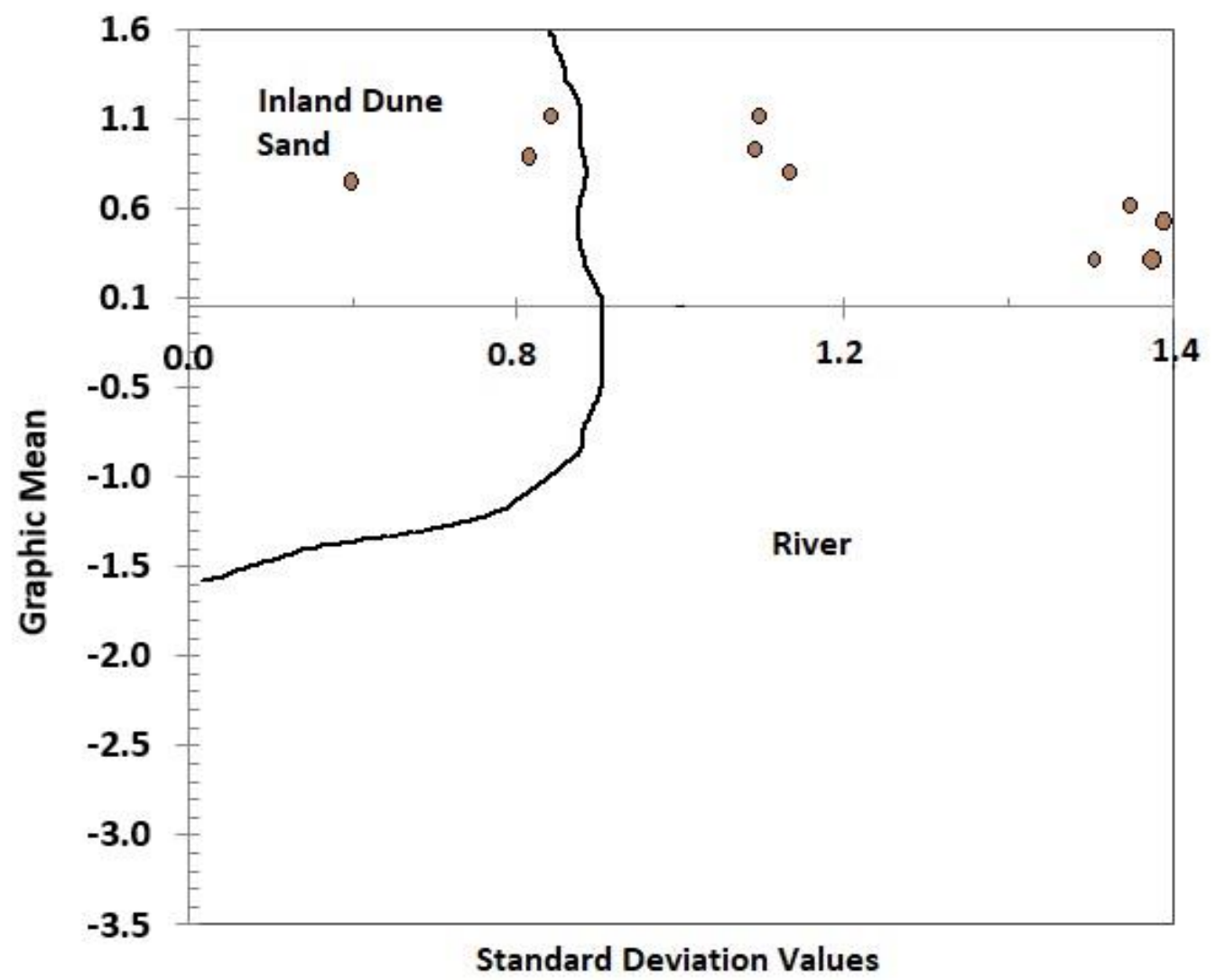

Figure 4. Bivariate plot of graphic mean versus inclusive standard deviation.

Table 1. Major element compositions (in wt. \%) of studied stream sediment samples.

\begin{tabular}{lcccccccccccc}
\hline Oxides & 1A & 1B & 1C & 2A & 2B & 3A & 3B & 4A & 4B & Min & Max & Mean \\
\hline $\mathrm{SiO}_{2}$ & 70.65 & 64.81 & 65.98 & 67.72 & 66.39 & 67.61 & 69.35 & 71.59 & 68.52 & 64.81 & 71.59 & 68.069 \\
$\mathrm{TiO}_{2}$ & 0.83 & 0.84 & 0.82 & 0.93 & 1.12 & 0.93 & 1.24 & 0.82 & 0.96 & 0.82 & 1.24 & 0.943 \\
$\mathrm{Al}_{2} \mathrm{O}_{3}$ & 10.73 & 12.44 & 10.85 & 10.96 & 10.81 & 13.3 & 11.82 & 10.4 & 9.77 & 9.77 & 13.3 & 11.231 \\
$\mathrm{Fe}_{2} \mathrm{O}_{3}$ & 2.44 & 3.94 & 3.69 & 3.24 & 3.67 & 2.54 & 2.33 & 3.59 & 5.16 & 2.33 & 5.16 & 2.402 \\
$\mathrm{MnO}$ & 0.05 & 0.09 & 0.07 & 0.06 & 0.06 & 0.04 & 0.04 & 0.1 & 0.17 & 0.04 & 0.17 & 0.076 \\
$\mathrm{MgO}$ & 0.13 & 0.21 & 0.15 & 0.43 & 0.44 & 0.27 & 0.26 & 0.12 & 0.11 & 0.11 & 0.44 & 0.235 \\
$\mathrm{CaO}$ & 0.27 & 0.26 & 0.26 & 0.36 & 0.36 & 0.32 & 0.33 & 0.17 & 0.16 & 0.16 & 0.36 & 0.276 \\
$\mathrm{Na} 2$ & 1.66 & 1.42 & 1.52 & 1.74 & 1.74 & 2.77 & 2.21 & 1.17 & 1.05 & 1.05 & 2.77 & 1.796 \\
$\mathrm{~K}_{2} \mathrm{O}$ & 3.11 & 3.41 & 3.09 & 3.31 & 3.38 & 3.75 & 3.43 & 3.89 & 3.67 & 3.09 & 3.89 & 3.449 \\
$\mathrm{P}_{2} \mathrm{O}_{5}$ & $<0.01$ & 0.01 & 0.02 & $<0.01$ & 0.02 & $<0.01$ & $<0.01$ & $<0.01$ & 0.11 & 0.01 & 0.11 & 0.04 \\
$\mathrm{LOI}$ & 0.36 & 0.26 & 0.31 & 0.37 & 0.37 & 0.41 & 0.28 & 0.42 & 0.36 & 0.26 & 0.42 & 0.34 \\
\hline
\end{tabular}

$\mathrm{TiO}_{2}$ values range from 0.82 to 1.24 wt.\% with a mean value of $0.92 \mathrm{wt} . \%$. The values are high in location 3B with value of 1.24 wt. $\% . \mathrm{Al}_{2} \mathrm{O}_{3}$ values range from 9.77 to 13.30 wt.\% with a mean value of 11.231 wt.\% close to its continental crust values (Ogunyele et al., 2019). A high value of $13.30 \mathrm{wt} . \%$ was observed in location $3 \mathrm{~A}$. The abundance of $\mathrm{Al}_{2} \mathrm{O}_{3}$ indicates that the samples were formed from $\mathrm{Al}$ rich source bed rock. $\mathrm{Fe}_{2} \mathrm{O}_{3}$ values range from 2.33 to $5.16 \mathrm{wt}$.\% with a mean value of $2.40 \mathrm{wt} . \%$ which is slightly lower than its continental crust value of 3.59 wt.\% (specifically granite gneiss). The highest concentration of $\mathrm{Fe}_{2} \mathrm{O}_{3}$ was in location 4B where the sediments are rich in iron-bearing minerals. The content of $\mathrm{Fe}$ is attributed to the weathered materials enriched in iron 
Table 2. Index of Geoaccumulation of trace elements.

\begin{tabular}{lccc}
\hline \multirow{2}{*}{ Element } & \multicolumn{3}{c}{ Index of Geoaccumulation $($ Igeo $)$} \\
\cline { 2 - 4 } & Min & Max & Mean \\
\hline $\mathrm{Sc}$ & 0.01 & 0.05 & 0.03 \\
$\mathrm{~V}$ & 0.03 & 0.1 & 0.1 \\
$\mathrm{Cr}$ & 0.1 & 0.14 & 0.07 \\
$\mathrm{Ni}$ & 0.02 & 0.23 & 0.07 \\
$\mathrm{Zn}$ & 0.02 & 0.09 & 0.05 \\
$\mathrm{Y}$ & 0.3 & 10.21 & 0.12 \\
$\mathrm{Zr}$ & 0.2 & 0.3 & 0.14 \\
\hline
\end{tabular}

oxide transported by water towards the stream bed. $\mathrm{CaO}$ values range from 0.16 to 0.36 wt.\% with a mean value of 0.28 wt.\%. The highest concentration of $\mathrm{CaO}$ was in locations $2 \mathrm{~A}$ and $2 \mathrm{~B}$. Other major oxides like $\mathrm{MgO}, \mathrm{Na}_{2} \mathrm{O}$, $\mathrm{MnO}, \mathrm{K}_{2} \mathrm{O}$ and $\mathrm{P}_{2} \mathrm{O}_{5}$ have mean values of $0.235,1.80$, $0.08,3.449$ and 0.04 wt.\% respectively. The high weight percentages of $\mathrm{SiO}_{2}$ and $\mathrm{Al}_{2} \mathrm{O}_{3}$ suggest felsic granitic rock and gneissic sources which coincidentally are found within the study area. Conversely, the weight percentages of $\mathrm{Fe}_{2} \mathrm{O}_{3}$ and $\mathrm{TiO}_{2}$ point to gneissic rock as a probable source rock.

The analyzed trace elements indicated that Vanadium (V) has a mean value of $26.89 \mathrm{ppm}$, Chromium (Cr) has a mean value of $32.33 \mathrm{ppm}$, Beryllium $(\mathrm{Be})$ has a mean value of $7.9 \mathrm{ppm}$ while Zirconium $(\mathrm{Zr})$ has mean value of $12.796 \mathrm{ppm}$. The mean Scandium (Sc) is $5.4 \mathrm{ppm}$. Zinc $(\mathrm{Zn})$ concentration varied from 9.71 to $36.3 \mathrm{ppm}$, with the mean content being $20.59 \mathrm{ppm}$. Yttrium $(\mathrm{Y})$ values range from 122 to $820 \mathrm{ppm}$, with the highest $Y$ content occurring in location 4B being $820 \mathrm{ppm}$. Nickel (Ni) values range from 4.51 to $21.6 \mathrm{ppm}$, with the highest $\mathrm{Ni}$ content occurring in location 2 and a total mean concentration value of $16.10 \mathrm{ppm}$. The level of concentration is acceptable as they are below most of the world's contamination level in soils (Duke, 1980; Chen et al., 1999; Cempel and Nikel, 2006). Duke (1980) reported an average natural nickel concentration of $86 \mathrm{ppm}$ in the earth crust. Contamination levels of $60 \mathrm{ppm}$ has been reported in sediments from Australia, 15 ppm from South Africa, 100 ppm from Brazil and 50 ppm from France.

Index of Geoaccumulation was calculated to check the level of accumulation and contamination of the stream sediment. Results are shown in Table 2. The index of geoaccumulation ( $\left.I_{\text {geo }}\right)$ is calculated using equation (4) (Muller, 1969);

$\mathrm{I}_{\text {geo }}=\log 2\left\{\frac{C n}{1.5 \times B n}\right\}$

Where $\mathrm{Cn}$ is sample concentration and $\mathrm{Bn}$ is background/baseline concentration of an element in known standard or published average upper continental crustal concentration (Rudnick and Gao, 2003). In this work, published upper continental crust concentration of elements were used as baseline and background values.

Generally, the mean index of geoaccumulation falls within a range of 0 to 1 , that is, class 1 signifying that samples from the study area are unpolluted to moderately polluted (Muller 1969 classification). This is also an indication that there has been little or no contamination of the stream sediments.

\section{Conclusion}

Results revealed that stream sediments in this study ranged generally from medium to coarse-grained and were moderately to poorly sorted with majority being poorly sorted. Such sediments could have been deposited under variable currents and velocities since they are composed of a wide range of sizes. Skewness values were mostly positive while just a little percentage (8.7\%) were negatively skewed. This clearly indicates that the sediments were deposited in a fluviatile depositional environment.

The dominance of $\mathrm{SiO}_{2}$ and $\mathrm{Al}_{2} \mathrm{O}_{3}$ within the streams sediment samples suggests felsic and gneissic rocks as the source rocks of the streams sediments in the study area. Moreover, the suggested rock types are also exposed in the study area. Thus, elemental distribution patterns and chemical composition of the streams sediments were greatly influenced by the geology of the area.

\section{CONFLICT OF INTEREST}

The authors declare that they have no conflict of interest.

\section{REFERENCES}

Adepoju, M. O., \& Adekoya, J. A. (2014). Heavy metal distribution and assessment in stream sediments of River Orle, Southwestern Nigeria. Arabian Journal of Geosciences, 7(2), 743-756.

Akintola, A. I., Ikhane P. R., Bankola, S. I., \& Adeokurolere, D. M. (2013). Petrography and stream sediment geochemistry of Ede and its environs, southwestern Nigeria. International Research Journal of Geology and Mining, 3(6), 235-256

Amaral, E. J., \& Pryor, W. A. (1977). Depositional environment of the St. Peter sandstone deduced by textural analysis. Journal of Sedimentary Research, 47(1), 32-52.

Cempel, M., \& Mikel, G. (2006). Nickel: A review of its sources and environmental toxicology. Polish Journal of Environmental Studies, 15(3), 375-382.

Chen, Z. S., Tsai, C. C., \& Tsui, C. C. (1999). Proposed regulation of soil pollutants in Taiwan soils. In: Proceedings of sixth workshop on soil pollution and prevention: Soil remediation techniques on soils contaminated by organic pollutants, Taipei, Taiwan. Pp. 169-207.

Duke, J. M. (1980). Production and uses of Nickel. In: J. O. Nriagu (ed). Nickel in the environment. John Wiley \& sons, New York. Pp. 51-65. 
Dziunikowski, B. (1989). Energy dispersive X-ray fluorescence analysis, Elsevier, Amsterdam-Oxford.

Folk, R. L. (1951). Stages of textural maturity in sedimentary rocks. Journal of Sedimentary Research, 21(3), 127-130.

Folk, R. L. (1980). Petrology of sedimentary rocks. Austin: Hemphill Publishing company. Pp. 16-184.

Folk, R. L., \& Ward, W. C. (1957). Brazos River bar [Texas]; a study in the significance of grain size parameters. Journal of Sedimentary Research, 27(1), 3-26.

Friedman, G. M. (1979). Address of the retiring president of the International Association of Sedimentologists: Differences in size distributions of populations of particles among sands of various origins. Sedimentology, 26(1), 3-32.

Gao, S., Luo, T. C., Zhang, B. R., Zhang, H. F., Han, Y. W., Zhao, Z. D., \& Hu, Y. K. (1998). Chemical composition of the continental crust as revealed by studies in East China. Geochimica et Cosmochimica Acta,62(11), 19591975.

Hawkes, H. E. (1976). The downstream dilution of stream sediment anomalies. Journal of Geochemical Exploration, 6(12), 345-358.
Muller, G. (1969). Index of geoaccumulation in sediments of the Rhine river. GeoJournal, 2, 108-118.

Odundun, O. A., \& Ogundoro, O. J. (2019). Origin and sandstone classification of the upper Cretaceous Lokoja sandstone in Southern Bida basin, as determined from geochemical data. Global Journal of Geological Sciences, 17, 1-11.

Ogunyele, A. C., Oluwajana, O. A., Ehinola, I. Q., Ameh, B. E., \& Salaudeen, T. A. (2020). Petrochemistry and petrogenesis of the Precambrian Basement Complex rocks around AkungbaAkoko, southwestern Nigeria. Materials and Geoenvironment, 66(3), 173-183.

Rahaman, M. A. (1988). Review of basement geology of southwestern Nigeria. In: Kogbe, C. A. (ed). Geology of Nigeria. Elizabethan Publication Co. Lagos. Pp. 41-58.

Rudnick, R. L., \& Gao, S. (2003). Composition of the continental crust. In: Rudnick, R. L. (ed.). Treatise on Geochemistry. Vol. 3. The Crust. Elsevier; Amsterdam. Pp. 1-64.

Visher, G. S. (1969). Grain size distributions and depositional processes. Journal of Sedimentary Research, 39(3), 10741106. 